\section{Effects of Reserpine on Secretion from the Adrenal Medulla}

IT is a well-established fact that reserpine causes a depletion of catechol amines ${ }^{12}$ in various organs. Whether this depletion is due to a decreased rate of synthesis or to an increased rate of release from the storage sites has not been clearly shown.

Changes in the content of catechols in the blood after administration of reserpine have been reported by Muscholl and Vogt ${ }^{3}$, who found in rabbits, using biossay, an increase in venous plasma adrenaline but no measurable change in noradrenaline. In contrast, Burger $^{4}$ reports in man a distinct fall in plasma noradrenaline and a slight fall in plasma adrenaline, as measured by a fluorimetric method.

In the experiments reported here the purpose has been to determine whether reserpine causes secretion of medullary hormones into the adrenal venous blood.

To cats of both sexes, weighing 3-4 kgm. and anæsthetized with 'Nembutal' (Abbott), given intraperitoneally, $3 \mathrm{mgm}$./kgm. reserpine ('Serpasil', Ciba) was administered intravenously. Collections of adrenal vein blood were made at intervals using a special shunt technique (Schapiro and Stjärne, to be published). The adrenal vein plasma and the organ extracts were assayed biologically (cat's blood pressure and hen's rectal cæcum).

Reserpine was found to cause a transitory fall in blood pressure in every experiment except one, in which both vagi had been cut and the carotid sinus denervated bilaterally. In this case a gradual pressor effect was observed, lasting for $20 \mathrm{~min}$. with a maximum value $40 \mathrm{~mm}$. mercury above the resting level.

In every experiment reserpine caused a well-marked increase in the secretion-rate of both adrenaline and noradrenaline. The increase was already present in the first collection period $10-15 \mathrm{~min}$. after reserpine was given; it reached its maximum value $1 \frac{1}{2}-2 \mathrm{hr}$. later (Fig. 1). The effect on noradrenaline secretion was consistently greater than that on adrenaline, noradrenaline making up $75-90$ per cent of the total catechols released. The amount of noradrenaline recovered in the adrenal vein blood in some experiments is so large that it suggests an increased rate of resynthesis, at least initially (Table 1).

The results of our experiments suggest that reserpine causes a relatively selective mobilization of noradrenaline. This is in accordance with the results reported by Eränkö and Hopsu. These workers have shown by histochemical methods in rats that reserpine causes typical secretory changes almost exclusively

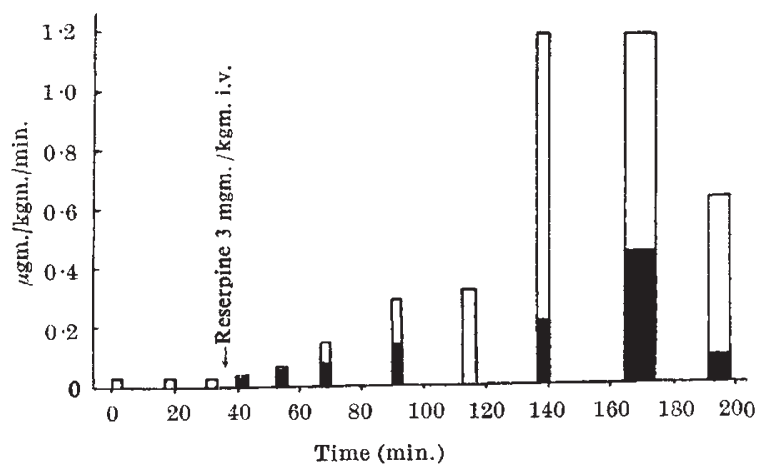

Fig. 1. Secretion of adrenaline and noradrenaline after the intravenous administration of $3 \mathrm{mgm} . / \mathrm{kgm}$. reserpine. White, noradrenaline; black, adrenaline Table 1. ADRENALINE AND NORADRENALINE IN THE ADRENAL IN THE ADRRNAL VEIN PLASMA AFTER RESERPINE

The calculation of the output is based on the assumption that during each shunt period the secretion can be represented by the average of the collection period immediately before and after it.

\begin{tabular}{|c|c|c|}
\hline $\begin{array}{c}\text { Weight of left adrenal gland, } \\
295 \mathrm{mgm} .\end{array}$ & $\begin{array}{c}\text { Adrenaline } \\
(\mu \mathrm{gm} .)\end{array}$ & $\begin{array}{c}\text { Noradrenaline } \\
(\mu \mathrm{gm} .)\end{array}$ \\
\hline $\begin{array}{c}\text { Content of left adrenal after the ex- } \\
\text { periment }(a)\end{array}$ & 62 & 15 \\
$\begin{array}{c}\text { Recovery in adrenal vein blood after } \\
\text { reserpine }(b) \\
\text { Total amount recovered }(a+b)\end{array}$ & 91 & 282 \\
\end{tabular}

in the parts of the adrenal medulla containing noradrenaline. The initially increased resynthesisrate observed by us during the first $2-3 \mathrm{hr}$. after the administration of reserpine is of special interest in view of reports (refs. 6 and 7 and Bygdeman, s., and von Euler, U. S., personal communication) showing that direct electrical stimulation of the splanchnic nerve causes an acceleration of synthesis. However, the dose of reserpine used by us is known to cause an almost complete emptying of the adrenal medulla in 16-24 hr. Thus it seems clear that in the long run resynthesis cannot keep pace with secretion.

Other experiments of ours (in preparation) as well as by others ${ }^{1,2} 8$ indicate that the effect of reserpine on the adrenal medulla is to a large extent dependent on the innervation of the gland being intact.

This investigation has been supported by a grant to one of us (L. S.) from Svenska Nationalföreningen mot Tuberkulos och andra Folksjukdomar.

\section{STJ ÄRNE}

S. SChAPIRO*

Department of Physiology,

Karolinska Institutet, Stockholm. July 29.

- Research Fellow of the Public Health Service, National Institute of Mental Health. Present address: Institute for Medical Research, Cedars of Lebanon Hospital, Los Angeles, California.

' Carlsson, A., and Hillarp, N. A., K. Fysiogr. Sällsk. Lund Förh., 26, 8 (1956).

${ }^{2}$ Holzbauer, M., and Vogt, M., J. Neurochem., 1, 8 (1956).

${ }^{3}$ Muscholl, E., and Vogt, M., Brit. J. Pharmacol., 4, 532 (1957).

4 Burger, M., Arch. Exp. Path. Pharmak., 230, 489 (1957).

5 Eränkö, O., and Hopsu, V., Endocrinol., 62, 15 (1958).

${ }^{6}$ Hökfelt, B., and McLean, J., Acta Physiol. Scand., 21, 258 (1950). 'Holland, W. C., and Schümann, Ir. J., Brit. J. Pharmacol., 11, 449 (1956).

${ }^{8}$ Kroneberg, G., and Schümann, II. J., Arzneim.-Forsch., 7, 279 (1957).

\section{Behaviour of 19-nor-Progesterone and 19-nor-Ethinyltestosterone in the Liver of the Guinea Pig.}

THE anticstrogenic properties of $9-\alpha$-fiuoro- $11-\beta$ hydroxyprogesterone are superior to those of 11- $\beta$ hydroxyprogesterone ${ }^{1}$. The halogenated compound resists inactivation in the liver ${ }^{2}$. This resistance has been corroborated in a new set of experiments (Table $1, A, B$ and $C$ ), from which it is evident that a given amount absorbed from an intrasplenic pellet $(B)$ is less active than when absorbed from a subcutaneous one $(A)$. There is no doubt, however, as to resistance of the halogenated compound in the liver (compare $B$ and $C$ with $\mathrm{I} b$ ). Thus greater activity, namely, enhanced antifibromatogenic, antihysterotrophic and antiluteinizing properties of the halogenated, as compared with the non-halogenated 